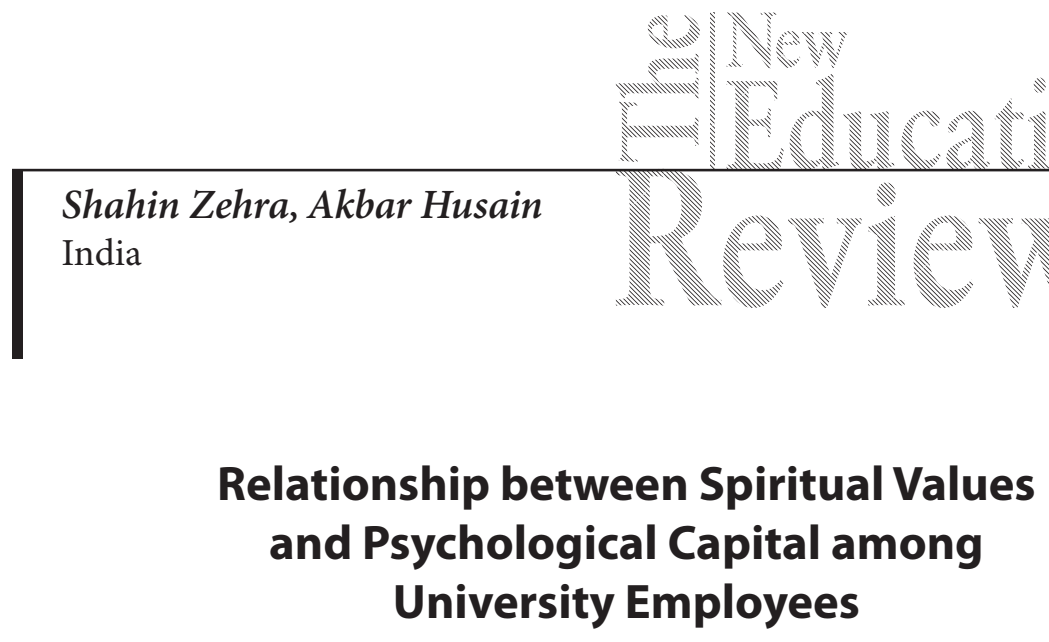

\title{
Abstract
}

There are no greater treasures than spiritual values of the employees for their development and organizational development. Psychological capital provides a combined construct as a main contributor to the competitive advantage of organisations. The construct adds the value of positive psychological resources to the existing best measure of organisational worth, comprised of the more established constructs of social capital, human capital, and traditional physical and financial capital. The presented study examined the relationship between Spiritual Values and Psychological Capital among 100 school teachers and 100 non-teaching staff of Aligarh Muslim University, Aligarh, India. A Spiritual Values Scale developed by Husain, Zehra and Jahan (in press), and a Psychological Capital Questionnaire by Luthans et al. (2007) were administered to them. The data were analyzed by means of Cronbach's alpha and multiple regression analysis. Cronbach's alpha for the total sample was found to be 0.947 . Significant positive correlation coefficients were found between spiritual values and self-efficacy, spiritual values and hope, and spiritual values and psychological capital among males, females and non-teaching staff members. Significant positive correlations were also found between spiritual values and self-efficacy, spiritual values and hope, spiritual values and resilience, spiritual values and optimism, and spiritual values and psychological capital among university employees.

Keywords: relationship, spiritual values, psychological capital 
Spirituality in the workplace as a concept indicates a sense of inter-connectedness with work and workmates, an ability to transcend the ordinary and to see work as sacred in everyday life. Through spirituality one gets the meaning and purpose of life, and does not feel alienated from work. Spiritual values such as compassion, trust, harmony, and sharing prevail making the person perform at an optimum level and sometimes even at a higher level, which the person usually does not think of achieving.

Values are the most important determinants of behaviour which direct the employees to the positive psychological resources consisting of efficacy, hope, optimism, and resilience. Organisations that promote spiritual values of the employees recognize that they seek to find meaning and purpose in their work, and desire to connect with psychological capital. Values broaden the individual's capacity for effective action and build upon their personal resources. This suggests that positive psychological resources require investment and development for the employees' to realize full capacities.

The presented study intended to examine the relationship between spiritual values and psychological capital among university employees. University is such an organisation which encourages exploration of connectedness with other organisational employees.

\section{Spiritual values}

Spiritual values essentially enhance our spiritual life and strengthen the attitude and mind. The best way to lead a spiritual life is to follow certain values which God has included in the Holy Scriptures. Spiritual values enrich our work life. It helps us to acquire a positive and spiritual foundation of life. To foster a spiritual attitude and develop personality are the spiritual goals of life. Our life is transformed through spiritual values. Spiritual values inculcate a strong desire in the individual to do something great in his life. Spiritual values activate one's mind and attitude to adopt a righteous path and to do hard work. Spiritual values are common to everyone because God does not discriminate between one person and another. Spiritual values are greater than any other type of values. Our spiritual life is healthy and meaningful, if we probe into our mind, thought and heart.

Spiritual values activate other states, which go beyond the bodily state. Spiritual values are the spiritual part of our life and help us to transform our energy and life in the positive direction. It makes our work life more meaningful. Spiritual values encourage and support employees and make them self-confident. Spiritual values 
develop the sense of hope, optimism, moral strength, and above all, assure us of the eternal nature of our soul. Spiritual values promote solely spiritual living.

Spiritual values are dynamic, not static; their full, fiery power transforms our mind. Spiritual values are real, eternal, infinite and imperishable, which leads to purity and bliss. Spiritual values are a dynamic beneficial source of strength and inspiration to all.

Spiritual values such as harmony, unity, peace, spiritual discipline, forbearance and truthfulness strengthen us in adversity and protect us from hardship and difficulties. They help us in transforming our thoughts and in bringing stability to the mind, which is necessary for confronting and resolving adversity in life, and righteous actions. Spiritual values give us purpose and meaning in life.

\section{Psychological Capital}

Luthans and Youssef (2004) provide a combined construct for the positive organisational behavior, i.e., psychological capital as a main contributor to the competitive advantage of organisations. The construct adds the value of positive psychological resources to the existing best measure of organisational worth, comprised of the more established constructs of social capital, human capital, and traditional physical and financial capital. Human capital refers to experience, education, knowledge, etc., or is simply "what you know", while social capital is "who you know." Social capital can be used both inside an organisation ("who can help me in this crisis?") and outside of it ("who can direct me to finding the best market in making this selling decision?"). There are so many ways to measure and evaluate social capital, involving the size, structure, and composition of networks.

Luthans and Youssef (2004) refer to the positive psychological resources consisting of confidence, hope, optimism, and resilience. Psychological capital consists of positive psychological capabilities that are assessable, open to enlarging, and manageable (Luthans \& Youssef, 2004). Peterson and Luthans (2003) found that all of these positive states had been discovered to some extent within the organisational literature and had importance in organisational research and practice. On the other hand, these constructs hardly ever appear in the employee's viewpoint, and only slightly more often in management scholars.

Luthans and Youssef (2004) illustrate the dimension of Psychological Capital, summarizing the way in which each state is defined within the incorporated construct. In addition, they emphasize that each of these states involves distinctiveness, sustainable competitive gain, and potential, is developable, and measurable 
and has an effect on performance. These attributes provide the standard criteria according to which the four dimensions, i.e., self-efficacy, hope, resilience and optimism have been selected.

\section{Dimensions of Positive Psychological Capital}

There are four dimensions of positive psychological capital. Positive psychological capital is a core construct, which goes beyond human and social capital.

Efficacy: According to Craig (2007), efficacy can be considered as 'Being certain in your own abilities..... and having trust in people, plans or the future'. No doubt, confidence (self-efficacy) is explained in the Psychological Capital model as "believing in one's ability to mobilize cognitive resources to obtain specific outcomes", (Luthans \& Youssef, 2004). Bandura (1997) defined perceived selfefficacy as "beliefs in one's capabilities to organise and execute the course of action required to produce given attainments".

In other words, efficacy offers a person a beneficial cognitive process and certain openness to challenge, and willingness to apply effort in the pursuit of a successful result even though the person expects a positive return on that investment. As dictated by the Positive Organisational Behaviour framework, the concept is quantifiable (Stajkovic \& Luthans, 1998), developable (Bandura, 1997), and has a clear impact on performance.

Hope: It is illustrated in the Psychological Capital model as "having the willpower and pathways to attain one's goals" (Luthans \& Youssef, 2004). In fact, hopeful people experience more positive feelings than those who have a more pessimistic approach towards life. This description is derived from Snyder et al. (1991), who described hope to be a motivational state whereby two elements, as goal-directed strength of mind and planning to achieve those goals, interact. Hope is both the existence of wish to attain goals or aims which imply an effect on or relationship to motivation and the capability to conceive a strategy for attaining those goals or aims. According to Snyder, Rand and Sigmon (2002), hope is considered as quantifiable, having a clear impact on performance, which can be enhanced.

Resilience: Resilience is another positive attribute which refers to a person's ability to overcome and often flourish from some substantial life events. Resilience 
in the Psychological Capital model is defined as "having the capacity to bounce back from adversity, failure or even positive, but seemingly overwhelming changes such as increased responsibility" (Luthans \& Youssef, 2004). Resilience has been paid the least attention in organisational literature. Certain events are often shocking, e.g., tragedy, disaster, accident, breakdown, failure, loss or catastrophe and they cause an individual to confront and cope with a situation that often affects others psychologically as well as negatively.

Luthans, Luthans and Luthans (2004) found that adding to the adaptive process the logical perception of reality, allowing for effective and rational responses to given circumstances and the inclination to seek or make meaning from events, allows people to "build bridges from present day hardship to a fuller, better constructed future", (Coutu, 2002). Resilience can be seen as having a clear impact on performance, can be measured, and might be developed at an individual level (Luthans \& Youssef, 2004).

Optimism: This state is illustrated in the Psychological Capital model as an "explanatory style that attributes positive events to internal, permanent and pervasive causes, and negative events to external, temporary, and situation-specific ones" (Luthans \& Youssef, 2004). It represents the definition employed by Seligman (2002), who described two dimensions of optimism in terms of the degree of durableness one perceives in a variable, and pervasiveness. Optimists will see a negative basis, e.g., as specific to an event and not to all events, and will see a positive cause in the reverse way.

The elements of optimism combine to impact on performance. Peterson and Luthans (2003) found that participants with an optimistic explanatory style improved in performance on a test after failure feedback, while those with a pessimistic one did not. Evidence suggests that optimism defined as above can be developed within individuals (Seligman, 1990).

Building on the foundation laid by Seligman, Luthans contends the need for the examination of positive organisational behaviour (Luthans, 2002), which moves beyond the popular style of self-help publications for practising managers towards research-baked, theoretically sound solutions to real-world problems. Thus, positive organisational behaviour is defined by Luthans (2002) as "The study and the application of positively oriented human resource strengths and psychological capacities that can be measured, developed, and effectively managed for performance improvement."

Howard and Welbourn (2004) reported that nearly $75 \%$ of UK workers would be interested in learning the spiritual aspect of their values, but $90 \%$ of UK man- 
agers believe that their organisations should not attempt to discuss the issue of spirituality with their employees.

Spiritual values can maximize and support the higher levels of potential and efficiency of employees. Employees who are self-confident, optimistic, resilient and hopeful in the workplace are very productive and they enrich the work environment for others. Employees who have faith on their values and psychological capital will be more productive. It is expected that spiritual values and the factors related to psychological capital will be responsible for real meaning, purpose and true personal development of university employees and organizational development.

\section{Research Objectives:}

1. To study the relationship between spiritual values and psychological capital among male and female employees.

2. To study the relationship between spiritual values and psychological capital among teaching and non-teaching employees.

\section{Hypotheses:}

1. There will be no relationship between spiritual values and psychological capital among male and female employees.

2. There will be no relationship between spiritual values and psychological capital among teaching and non-teaching employees.

\section{$\underline{\text { Research Methodology }}$}

Participants: Two hundred teaching and non-teaching employees were selected from Aligarh Muslim University, Aligarh. Of these, there were a hundred male and a hundred female employees. They were selected on the basis of a simple random sampling procedure. The age range of the employees was from 25 to 60, with an average age of 43 .

\section{Tools}

\section{Spiritual Values Scale}

It was developed by Husain, Zehra and Jahan (2013). This scale consists of 15 items with a 5-point Likert scale. SVS measures three factors: values fostering high quality work, intrinsic qualities and natural qualities. The internal consistency (Cronbach's Alpha) reliability for this scale is 0.887 . 


\section{Psychological Capital (PsyCap) Questionnaire}

The Psychological Capital Questionnaire (PsyCap), developed by Luthans, Youssef and Avolio (2007) and empirically validated by Luthans, Avolio et al. (2007), was used in this study. The internal consistency (Cronbach's Alpha) reliability for this scale is .92 . Specifically, the instrument consists of six items adapted from each of the following scales: (F1) Efficacy (Parker, 1998); (F2) Hope (Snyder et al., 1996); (F3) Resilience (Wagnild \& Young, 1993); and (F4) Optimism (Scheier \& Carver, 1985). The PsyCap consists of 24 items with a 6-point Likert-type scale: 1 - strongly disagree, 2 disagree, 3- somewhat disagree, 4- somewhat agree, 5- agree, and 6- strongly agree.

\section{Procedure}

For data collection, all the participants were contacted individually in their respective workplaces. A cordial rapport was established with all the participants. They were asked to give their personal details such as name, age, qualifications, and job profiles. After the establishment of rapport, they were provided the scales. They were asked to read the instructions carefully and respond frankly to all the items.

\section{Statistical Analysis}

The data was analyzed by means of Pearson Product Moment correlation.

\section{Results}

Table 1. Coefficients of correlation between spiritual values and psychological capital and factors of psychological capital among employees

\begin{tabular}{|c|c|c|c|c|c|}
\hline Variables & Self-Efficacy & Hope & Resilience & Optimism & Total PsyCap \\
\hline Total & $.437^{\star *}$ & $.496^{* *}$ & $.199^{\star *}$ & .117 & $.410^{\star *}$ \\
\hline Male & $.478^{\star \star}$ & $.546^{\star \star}$ & .137 & .137 & $.404^{\star \star}$ \\
\hline Female & $.401^{\star *}$ & $.311^{\star *}$ & .194 & .043 & $.346^{\star *}$ \\
\hline Teaching & $.463^{\star *}$ & $.550^{\star *}$ & $.251^{\star}$ & $.203^{*}$ & $.476^{\star *}$ \\
\hline Non-teaching & $.397^{\star *}$ & $.418^{\star *}$ & .129 & -.030 & $.309^{\star *}$ \\
\hline
\end{tabular}

${ }^{*} \mathrm{p}<.05{ }^{* *} \mathrm{p}<.01$

The coefficient of the correlation between spiritual values and efficacy is shown in Table 1 . Results revealed that spiritual values and efficacy were found to be positively correlated $(\mathrm{r}=.437, \mathrm{p}<.01)$ in the total sample. Significant positive correlations were also found between both the variables in the male $(r=.478$, $\mathrm{p}<.01)$ and female $(\mathrm{r}=.401, \mathrm{p}<.01)$ employees. Significant positive correlations 
were also found in the teaching $(\mathrm{r}=.463, \mathrm{p}<.01)$ and non-teaching $(\mathrm{r}=.397, \mathrm{p}<.01)$ employees. Results suggest that the employees' spiritual values determine the level of self-efficacy. Values influence the employees' behavior and the goals they set for themselves. The efficacy level of the employees helps to set new challenges and efforts in the pursuit of a successful result even though they expect a positive return on that investment.

Results revealed that spiritual values and hope were positively correlated $(\mathrm{r}=.496, \mathrm{p}<.01)$ in the total sample. Hope determines how to attain goals or aims to motivate the capability to conceive a strategy for attaining those goals or aims. The significant positive correlations were also found in the male $(\mathrm{r}=.546, \mathrm{p}<.01)$ and female $(\mathrm{r}=.311, \mathrm{p}<.01)$ employees. Significant positive correlations were also found in the teaching $(\mathrm{r}=.550, \mathrm{p}<.01)$ and non-teaching $(\mathrm{r}=.418, \mathrm{p}<.01)$ employees. Hopeful employees have high spiritual values. Hope is constructive cognition, which makes an individual dynamic and hopeful. The presented research suggests that the hope and spiritual values of the employees exhibit higher spirituality and better adjustment in the workplace.

As seen in Table 1, spiritual values and resilience are positively correlated $(\mathrm{r}=.199, \mathrm{p}<.01)$ in the total sample, and in the teaching employees $(\mathrm{r}=.251, \mathrm{p}<.05)$. Significant correlations were not found between the two variables in the male, female and non-teaching employees. Resilience is likely to be positively related to spiritual values because those employees who are able to cope with stress make an effort to improve their performance. Resilience is generally associated with predicting well-being in most of the situations.

The coefficient of correlations was not found between spiritual values and optimism in the total sample $(\mathrm{r}=.117 \mathrm{p}>.05)$, the male $(\mathrm{r}=.137 \mathrm{p}>.05)$ and female $(\mathrm{r}=.043 \mathrm{p}>.05)$, and non-teaching $(\mathrm{r}=-.030 \mathrm{p}>.05)$ employees. A positive correlation was found between both variables in the teaching employee $(r=.203, p<.05)$. Like hope, optimism is also constructive cognition, which helps an employee to attribute negative outcomes to external factors. The employees with spiritual values and optimism approach a difficult task as a challenge to be mastered rather than to be avoided.

The optimistic employees are more achievement-oriented in any task in their life. They take better decisions and maintain work-life balance. The optimistic, confident and hopeful employees report a higher quality of life, job satisfaction and are less likely to develop physical illness when they face major stressful life events than employees with a pessimistic style.

Results revealed that spiritual values were positively correlated with psychological capital $(.410, \mathrm{p}<.01)$ in the total sample, in the male $(.404, \mathrm{p}<.01)$ and female 
$(.346, \mathrm{p}<.01)$, teaching $(.476, \mathrm{p}<.01)$ and non-teaching $(.309, \mathrm{p}<.01)$ employees. The employees with positive psychological capital tend to show better performance, enjoy workplace tasks, have satisfaction, good health, confidence in coping, social support, respect for diversity. These employees tend to show passion and a positive attitude towards work, which lead to happiness, concern for family and society, spirituality, achievement, and positive affect. However, factors like communication in the workplace, nature of work, relationship with co-workers, supervision, reward, benefits and income play a very important role in the development of psychological capital in employees.

\section{Conclusion}

The findings of the presented study have led to the conclusion:

- Spiritual values were found to be significantly positively correlated with psychological capital among the male, female, teaching and non-teaching employees.

In sum, it can be concluded that employees' spiritual values are significantly positively associated with positive psychological capital. Spiritual values are a very important aspect of human existence. Organisations have to instill efficacy, hope, resilience and optimism in their employees. These states are positive in nature.

\section{$\underline{\text { Implications }}$}

Employers and organizations should start to believe that sustainable success helps employees to pursue and reach personal unique potential on the basis of their spiritual values and self-efficacy, hope, optimism and resilience factors. When they develop they inevitably become more effective and valuable as employees.

\section{References}

Bandura, A. (1997). Self-efficacy: The exercise of control. New York: Freeman. Coutu, D.L. (2002). How resilience works? Harvard Business Review, 80(5), 46-55.

Craig, C. (2007). Creating Confidence: A handbook for professionals working with young people. Glassgow: The centre for Confidence and Well-being. 
Demerouti, E., Bakker, A.B., Nachreiner, F., \& Schaufeli, W.B. (2001). The jobdemands-resources model of burnout. Journal of applied Psychology, 86, 499-512.

Fredrickson, B.L. (2001). The role of Positive emotions in positive psychology: The broaden-and-build theory of positive emotions. American Psychologist, 56, 218-226.

Luthans, F. (2002). The need for and meaning of positive organizational behaviour. Journal of Organizational Behavior, 23, 695-706.

Luthans, F., \& Youssef, C.M. (2004). Human, social and now positive psychological capital management. Organizational Dynamics, 33, 143-160.

Luthans, F., Avolio, B.J., Avey, J.B., \& Norman, S.M. (2007). Positive psychological capital: Measurement and relationship with performance and satisfaction. Personnel Psychology, 60, 541-572.

Luthans, F., Luthans, K. \& Luthans, B. (2004). Positive psychological capital: going beyond human and social capital. Business Horizons, 47(1), 45-50.

Luthans, F., Youssef, C.M., \& Avolio, B.J. (2007). Psychological Capital: Developing the human competitive edge, Oxford: Oxford University Press.

Maddux J.E. (2002). Self-efficacy: The power of believing you can. In C.R. Snyder \& S.J. Lopez (Ed.), Handbook of Positive Psychology, (pp.277-287), New York: Oxford University press.

Parker, S.K. (1998). Role of breadth self-efficacy: Relationship with work enrichment and other organizational practices. Journal of Applied Psychology, 83, 835-852.

Peterson, S.J., \& Luthans, F. (2003). The positive impact and development of hopeful leaders. Leadership and Organization Development Journal, 24, 26-31.

Scheier, M.F., \& Carver, C.S. (1985). Optimism, coping, and health: Assessment and implications of generalized outcome expectancies. Health Psychology, 4, 219-247.

Seligman, M.E.P. (1990). Learned Optimism. Sydney: Random House.

Seligman, M.E.P. (2002). Authentic Happiness. New York: Free Press.

Snyder, C.R., Harris, C., Anderson, J.R., Holleran, S.A., Irving, L.M., Sigmon, S.T., Yoshinobu, L., Gibb, J., Langelle, C., \& Harney, P. (1991). The will and the ways: Developments and validation of an individual-differences measure of hope. Journal of Personality and Social Psychology, 60, 570-585.

Snyder, C.R., Rand, K.L. \& Sigmon, D.R. (2002). Hope theory: A member of the positive psychological family. In C.R. Snyder \& S.J. Lopez (Eds.), Handbook of Positive Psychology, (pp.257-276), New York: Oxford University press. 
Snyder, C.R., Sympson, S.C., Ybasco, F.C., Borders, T.F., Babyak, M.A., \& Higgins, R.L. (1996). Development and Validation of the State Hope scale. Journal of Personality and Social Psychology, 70 (2), 321-335.

Stajkovic, A. \& Luthans, F. (1998). Self-efficacy and work-related performance: A meta-analysis. Psychological Bulletin, 44, 580-590.

Sweetman, D., \& Luthans, F. (2010). The power of positive psychology: psychological capital and work engagement. In A.B. Bakker, M.P. Leiter, (Eds.) Work engagement: A handbook of essential theory and research (pp.54-68). Psychology Press: Hove.

Wagnild, G., \& Young, H. (1993). Development and psychometric evaluation of the resilience scale. Journal of Nursing Measurement, 1 (2), 165-178. 